\title{
Produção de novilhas de corte em pastagem de Coastcross-1 consorciada com Arachis pintoi com e sem adubação nitrogenada
}

\author{
Wagner Paris ${ }^{1 *}$, Ulysses Cecato² ${ }^{2}$ Antonio Ferriani Branco ${ }^{2}$, Leandro Martins Barbero ${ }^{3}$, \\ Sandra Galbeiro ${ }^{1}$
}

\footnotetext{
${ }^{1}$ Doutorado do Programa de Pós-graduação em Zootecnia da UEM.

2 Departamento de Zootecnia da UEM.

${ }^{3}$ Mestrado do Programa de Pós-graduação em Zootecnia da UEM.
}

RESUMO - Este trabalho foi realizado com o objetivo de avaliar a massa de forragem (MF), a taxa de acúmulo diário (TAD), a oferta de forragem (OF), a taxa de lotação (TL), a porcentagem de Arachis pintoi (PAR), o ganho médio diário (GMD) e o ganho por hectare (GPV/ha) de novilhas de corte em pastejo de Coastcross-1 consorciada com Arachis pintoi. Os consórcios avaliados foram: CA0 $=$ coastcross + Arachis pintoi sem adubação nitrogenada; CA100 = coastcross + Arachis pintoi com 100 kg de nitrogênio; CA200 = coastcross + Arachis pintoi com 200 kg de nitrogênio; e C200 = coastcross com 200 kg de nitrogênio, distribuídos em delineamento de blocos ao acaso, com duas repetições. O manejo do pasto foi o de lotação continua com carga animal variável utilizando-se novilhas mestiças com três animais-testes por consórcio. A massa de forragem nas pastagens de coastcross + Arachis pintoi adubadas com 0, 100 e $200 \mathrm{~kg}$ de nitrogênio e na pastagem de coastcross adubada com $200 \mathrm{~kg}$ de nitrogênio foi de 2.641, 2.431, 2.760 e $2.704 \mathrm{~kg}$ de MS/ha, respectivamente. A taxa de acúmulo diário foi semelhante (66,12 kg de MS/ha) entre as pastagens; o verão foi a estação de maior produção, seguido da primavera, do outono, que não diferiram entre si, e do inverno (108,6; 71,1; 54,2; 30,6 kg de MS/ha, respectivamente). Na associação de coastcross + Arachis pintoi sem adubação nitrogenada, foram obtidas a maior oferta de forragem e a menor taxa de lotação (4,0 UA/ha). As maiores taxas de lotação e as menores ofertas de forragem foram observadas com a adubação nitrogenada. A porcentagem de Arachis pintoi foi maior na primavera e, na associação coastcross + Arachis pintoi sem adubação, as estimativas visuais foram sempre superiores às medidas, em virtude do baixo teor de matéria seca dessa leguminosa. O ganho médio diário foi maior no cultivo em consórcio e adubação com 200 kg de nitrogênio e na pastagem de coastcross em cultivo exclusivo com 200 kg de nitrogênio em comparação àquelas de coastcross + Arachis adubada com $100 \mathrm{~kg}$ de nitrogênio e sem adubação (0,51; 0,51; 0,42 e 0,38 kg/dia, respectivamente). Os ganhos anuais por hectare foram superiores a $1.000 \mathrm{~kg} / \mathrm{ha} / \mathrm{ano}$ e foram maiores no verão (221,4 kg/ha)

Palavras-chave: bovino a pasto, desempenho animal, produção de massa de forragem, taxa de lotação

\section{Beef heifer production in Coastcross-1 and Arachis pintoi mixed pasture with or without nitrogen fertilization}

\begin{abstract}
This trial was carried out to evaluate forage mass (FM), daily accumulation rate (DAR), forage offer (FO), stocking rate (SR), Arachis pintoi percentage (APP), average daily gain (ADG) and gain per hectare (GPH) of beef heifers under grazing in Coastcross-1 and Arachis pintoi mixed pasture during different seasons, from July 2003 to June 2004. The treatments were: CA0 $=$ Coastcross + Arachis pintoi without N; CA100 $=$ Coastcross + Arachis pintoi with $100 \mathrm{~kg}$ of N; CA200 = Coastcross + Arachis pintoi with $200 \mathrm{~kg}$ of N; and C200 = Coastcross with $200 \mathrm{~kg}$ of N, distributed in a randomly block design, with two repetitions. Pasture management was done through continuous grazing with variable stocking rate, using crossbred heifers with three test animals per treatment. The FM was 2641, 2431, 2760 and $2704 \mathrm{~kg}$ of DM/ha for CA0, CA100, CA200 and C200, respectively. Treatments presented similar DAR (66.12 kg of DM/ha) between pastures, with higher production in the summer, followed by spring and autumn, which were not different from each other, and the winter with the lowest value: 108.6; 71.7; 54.2; $30.6 \mathrm{~kg}$ of DM/ha, respectively. In the CA0 treatment, the highest FO and the lowest SR were obtained (4.0 AU/ha). The highest SR and lowest FO were observed in treatments with nitrogen fertilization, without difference among them. The APP in the mixture was higher in the spring, and for the CA0 treatment, with visual estimations were always higher in function of the lower dry matter percentage of this legume. For ADG was higher for CA200 and C200 treatments in relation to CA100 and CA0 with values of 0.51, 0.51, 0.42 and $0.38 \mathrm{~kg} /$ day, respectively. The GPH were above $1000 \mathrm{~kg} / \mathrm{ha} / \mathrm{year}$ and the summer presented the highest gain $(221.4 \mathrm{~kg} / \mathrm{ha})$.
\end{abstract}

Key Words: animal performance, forage mass production, grazing cattle, stocking rate 


\section{Introdução}

Nos sistemas de produção em pastagem no Brasil, não ocorre o total aproveitamento do potencial produtivo, uma vez que prevalece a metodologia extrativista, que resulta em índices zootécnicos ineficientes. A taxa de lotação, média de 0,85 UA/ha, é menor que a obtida em alguns países de clima temperado, onde o potencial produtivo é menor ( $\mathrm{Da}$ Silva \& Sbrissa, 2000).

O uso da adubação nitrogenada é recomendável para aumentar a densidade da forragem e, sobretudo, a disponibilidade de folhas. Ao acelerar a taxa de crescimento, independentemente da altura do pasto, o nitrogênio pode propiciar o aumento do consumo - por elevar a produção de matéria seca dentro dos estratos verticais da pastagem (Heringer \& Moojen, 2002) - e da produção por área (Primavesi et al., 2004).

O manejo adequado das pastagens possibilita o aumento da produção animal por área, via combinação ótima de rendimento forrageiro e eficiente conversão da massa produzida em produto animal. Enquanto o rendimento forrageiro depende das condições de solo e clima, das características da espécie e de seu manejo, a conversão da forragem em produto animal depende do seu valor nutritivo, do consumo e da capacidade genética do animal.

Em decorrência da aplicação de nitrogênio, geralmente observa-se incremento na produção da massa seca, principalmente em forrageiras com alto potencial de produção. Cantarutti (1997) propôs a utilização do consórcio gramínealeguminosa para favorecer as taxas de reciclagem do nitrogênio e incrementá-lo via fixação biológica. A produtividade nestas condições está diretamente relacionada a adaptações que permitem às plantas absorver, reduzir, assimilar e translocar eficientemente o nitrogênio do solo, além de outras adaptações no metabolismo fotossintético.

Além da fixação do nitrogênio, as leguminosas também contribuem para o aumento do teor de proteína bruta ingerida pelos animais. Dessa forma, as espécies de Arachis são leguminosas tropicais interessantes, com alto valor como forrageira e densa cobertura do solo, chamadas "alfafa das savanas", em virtude de seu valor nutritivo e sua palatabilidade (Valle, 2001).

O Arachis pintoi persiste ao pastejo por ter hábito de crescimento prostrado, habilidade de enraizar nos estolhos e reserva de sementes no solo (Jones, 1993). É bastante persistente em consorciação com Brachiaria dictyoneura, mesmo quando submetido a taxas de lotação de até 4 novilhos/ha (Santana et al., 1998). Cresce bem em amplitude de solos desde pesados argilosos a arenosos, mas possui melhor crescimento quando em solos arenoargilosos, desde que não haja limitação de umidade (Pizarro, 2001).

A consorciação de leguminosas e gramíneas perenes em condições tropicais pode resultar em melhorias tanto do pasto como da produção animal, por seu efeito indireto sobre a biodiversidade do ecossistema de pastagens e o aporte de nitrogênio, ou pelo efeito direto na dieta animal (Barcelo \& Vilela, 1994; Nascimento, 1996; Pizarro, 2001).

Avaliou-se neste trabalho o desempenho animal utilizando as medidas de produção de massa e oferta de forragem, taxa de lotação, ganho médio diário e ganho de peso vivo por hectare de novilhas mestiças em pastagem de Coastcross-1 (Cynodon dactylon (L.) Pers) consorciada com Arachis pintoi (Arachis pintoi Krapovickas y Gregori cv. Amarillo) com e sem adubação nitrogenada.

\section{Material e Métodos}

O experimento foi conduzido na Estação Experimental do IAPAR, em Paranavaí, no período de julho de 2003 a junho de 2004 , a $23^{\circ} 05^{\prime} \mathrm{S}$ de latitude e $42^{\circ} 26^{\prime} \mathrm{W}$ de longitude e altitude de $480 \mathrm{~m}$, tipo climático Cfa pela classificação de Köopen (IAPAR, 1994), com temperatura e precipitação pluviométrica anual média de $22,1^{\circ} \mathrm{C}$ e $1.400 \mathrm{~mm}$, respectivamente (Figura 1). O solo é classificado como Latossolo Amarelo distrófico (EMBRAPA, 1999), com 88\% de areia, $2 \%$ de silte e $10 \%$ de argila.

A área experimental, equivalente a 5,3 ha, foi utilizada durante três anos com integração lavoura e pecuária. O período foi encerrado no final do inverno de 2000 e, em novembro de 2000, a pastagem de coastcross foi implantada por mudas em covas. Cerca de 30 dias após o plantio da gramínea, as sementes de Arachis pintoi foram inoculadas com estirpe específica de Rhizobium e

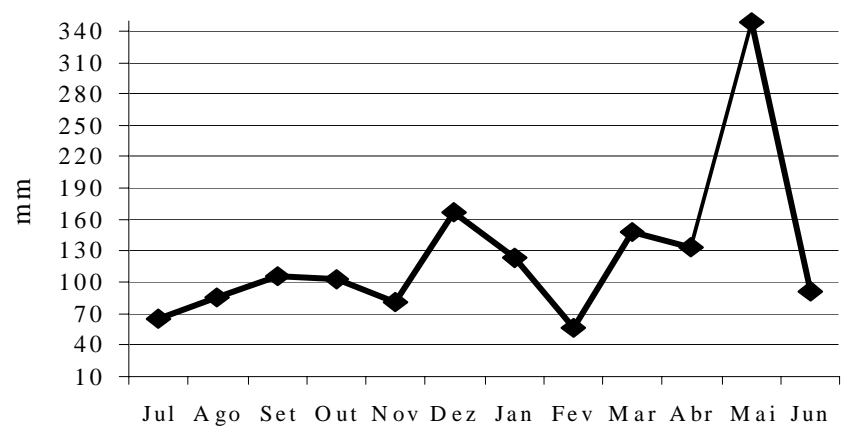

Mês

Figura 1 - Precipitação pluviométrica no período de julho de 2003 a junho de 2004. Estação Agrometerológica do IAPAR, Paranavaí, Paraná. 
plantadas por plantio direto mecanizado. A pastagem foi considerada formada em dezembro de 2001 e, depois do controle de plantas daninhas e uniformização da área, foi dividida em oito piquetes de mesmo tamanho. Durante o ano de 2002 e início de 2003, foi conduzido na área um ensaio de desempenho animal com novilhas de corte (Oliveira, 2004).

O experimento foi realizado no período de julho de 2003 a junho de 2004 totalizando quatro períodos de avaliação (inverno, primavera, verão e outono). Os animais foram distribuídos aleatoriamente nos piquetes, em delineamento experimental de blocos casualizados com duas repetições, composto pelos consórcios: CA0 $=$ coastcross + Arachis pintoi sem nitrogênio; CA100 = coastcross + Arachis pinto $i$ com 100 kg de nitrogênio; CA200 = coastcross + Arachis pintoi com $200 \mathrm{~kg}$ de nitrogênio e C200 = coastcross com $200 \mathrm{~kg}$ de nitrogênio. Para as adubações nitrogenadas, utilizaram-se nitrato de amônia (32\%) e uréia (68\%), em duas aplicações (a primeira no dia 1/12/2003 e a segunda no dia 23/1/2004). Na adubação de fósforo, realizou-se uma única aplicação, no dia 1/12/2003. As adubações de fósforo e de potássio foram realizadas de acordo com os resultados da análise de solo (Tabela 1).

No manejo do pasto, utilizou-se o método de lotação contínua mantendo-se ofertas de forragem médias de 10,6; 8,7; 9,5 e 9,0 kg de MS para $100 \mathrm{~kg}$ de peso vivo nas pastagens cultivadas em consórcio (coastcross + Arachis pintoi) e adubação com 0, 100 e 200 kg de nitrogênio e na pastagem de capim-coastcross exclusivo adubada com $200 \mathrm{~kg}$ de nitrogênio. Durante o período experimental, utilizou-se um grupo de 24 novilhas mestiças com peso vivo médio inicial de 160 a 180 kg, com três animais-teste por piquete, com livre acesso a água e sal mineral. Para controle da pressão de pastejo, foram utilizados animais reguladores visando adequação da massa de forragem em $2.500 \mathrm{kgMS} / \mathrm{ha}$, segundo a técnica de lotações variáveis (Mott \& Lucas, 1952).

A disponibilidade de forragem foi determinada utilizando-se a técnica de dupla amostragem (Wilm et al., 1944), com a coleta ao acaso de quatro amostras e mais dez avaliações visuais por piquete utilizando-se um quadrado de $0,25 \mathrm{~m}^{2}$. As coletas foram realizadas rente ao solo, a cada 28 dias. Para cálculo da disponibilidade de massa seca por área, foi utilizada a equação proposta por Gardner (1986). As amostras colhidas na dupla-amostragem foram utilizadas para separação do coastcross e do Arachis pintoi e obtenção da porcentagem de gramínea e de leguminosa. A composição botânica foi estimada visualmente por três avaliadores durante a dupla amostragem.

As avaliações de produção animal e da pastagem foram realizadas a cada 28 dias e, para melhor aferição da estacionalidade, foram agrupadas em quatro períodos: inverno (7/2003 a 9/2003); primavera (10/2003 a 12/2003); verão (1/2004 a 3/2004) e outono (4/2004 a 6/2004). A técnica do triplo emparelhamento com duas gaiolas de exclusão foi empregada para avaliação da taxa de acúmulo de massa de forragem nos piquetes, calculada pela equação descrita por Campbell (1966): $\operatorname{TAD}_{\mathrm{j}}=\left(\mathrm{G}_{\mathrm{i}}-\mathrm{F}_{\mathrm{i}-1}\right) / \mathrm{n}$, em que: $\mathrm{TAD}_{\mathrm{j}}=$ taxa de acúmulo diário de matéria seca no período j, em kg $\mathrm{MS} / \mathrm{ha} / \mathrm{dia} ; \mathrm{G}_{\mathrm{i}}=$ matéria seca dentro das gaiolas no instante i, em kg MS/ha; $\mathrm{F}_{\mathrm{i}-1}=$ matéria seca fora das gaiolas no instante i-1, em kg MS/ha; $\mathrm{n}$ = número de dias do período $\mathrm{j}$. O acúmulo de matéria seca nos períodos experimentais foi calculado multiplicando-se o valor de taxa de acúmulo diário pelo número de dias do período.

A taxa de lotação (TL) por piquete foi calculada considerando a unidade animal (UA) de $450 \mathrm{~kg}$ de PV, utilizando-se a seguinte fórmula: $\mathrm{TL}=\mathrm{UAt} /$ Área, em que: $\mathrm{TL}=$ taxa de lotação, em UA/ha; UAt = unidade animal total; área = área experimental, em ha.

O cálculo da oferta de forragem foi realizado para o controle da taxa de lotação utilizando-se a seguinte equação: $\mathrm{OF}=(\mathrm{RMSd}+\mathrm{TAD}) / \mathrm{CA}$, em que: $\mathrm{OF}=$ oferta de forragem, em kg MS/dia/100 kg PV; RMSd = resíduo de matéria seca diário, em kg MS/dia/ha; TAD = taxa de acúmulo diário, em $\mathrm{kg}$ MS/dia/ha; CA = carga animal, em kg/ha.

A avaliação do desempenho animal foi realizada por meio do controle de peso a cada 28 dias. O ganho médio diário animal, em kg por dia (GMD), foi obtido pela média da

Tabela 1 - Resultados das análises de solo da área experimental na profundidade 0 a 20 cm

\begin{tabular}{|c|c|c|c|c|c|c|c|c|c|}
\hline \multirow{2}{*}{ Forma de cultivo } & $\mathrm{P}$ & $\mathrm{C}$ & $\mathrm{pH}$ & $\mathrm{Al}$ & $\mathrm{H}+\mathrm{Al}$ & $\mathrm{Ca}$ & $\mathrm{Mg}$ & K & V \\
\hline & $\mathrm{mg} / \mathrm{dm}^{3}$ & $\mathrm{~g} / \mathrm{dm}^{3}$ & \multicolumn{6}{|c|}{$\mathrm{cmol}_{\mathrm{c}} / \mathrm{dm}^{3}$ de solo } & $\%$ \\
\hline CA0 & 9,87 & 10,16 & 4,95 & 0,04 & 2,59 & 1,34 & 1,01 & 0,17 & 48,97 \\
\hline CA200 & 5,67 & 9,93 & 4,50 & 0,11 & 3,00 & 1,15 & 0,70 & 0,18 & 39,88 \\
\hline C200 & 4,42 & 8,62 & 4,35 & 0,16 & 3,18 & 0,98 & 0,63 & 0,14 & 35,32 \\
\hline Média & 6,39 & 9,42 & 4,58 & 0,11 & 2,15 & 1,14 & 0,79 & 0,15 & 41,36 \\
\hline
\end{tabular}

CA0 $=$ coastcross + Arachis pintoi sem nitrogênio; CA100 = coastcross + Arachis pintoi com 100 kg de nitrogênio; CA200 = coastcross + Arachis pintoi com 200 kg de nitrogênio; e C200 = coastcross com 200 kg de nitrogênio. 
diferença entre o peso de entrada e saída dos animais-teste, dividido pelo número de dias que permaneceram nos piquetes. O ganho de peso vivo por unidade de área (GPV/ha) foi calculado pelo produto do número de animais por hectare, pelos dias de permanência e pelo ganho médio diário dos animais-teste.

As variáveis relacionadas ao acúmulo de forragem e ao desempenho animal foram submetidas a análise de variância e as médias comparadas pelo teste Tukey a 5\% de probabilidade. As análises foram realizadas por intermédio do programa SAEG - Sistemas de Análises Estatísticas e Genéticas (UFV, 1997) utilizando-se o seguinte modelo estatístico: $\mathrm{Y}_{\mathrm{ijk}}=\mu+\mathrm{T}_{\mathrm{i}}+\mathrm{B}_{\mathrm{j}}+\mathrm{P}_{\mathrm{k}}+\mathrm{TB}_{\mathrm{ij}}+\mathrm{TP}_{\mathrm{ik}}+$ $\mathrm{e}_{\mathrm{ijk}}$, em que: $\mathrm{Y}_{\mathrm{ijkl}}=$ valor da variável observado no piquete com o consórcio i e encontra-se no bloco j; $\mu$ = média geral; $\mathrm{T}_{\mathrm{i}}=$ efeito do consórcio $\mathrm{i}$, de modo que $\mathrm{i}=1,2,3,4 ; \mathrm{B}_{\mathrm{j}}=$ efeito do bloco j, j =1,2; $\mathrm{P}_{\mathrm{k}}=$ efeito do período $\mathrm{k}$, de modo que $\mathrm{k}$ $=1,2,3,4 ; \mathrm{TB}_{\mathrm{ij}}=$ efeito da interação consórcio $\times$ blocos; $\mathrm{TP}_{\mathrm{ik}}=$ efeito da interação consórcio $\times$ período; $\mathrm{e} \mathrm{e}_{\mathrm{ilk}}=$ erro aleatório atribuído a cada observação, $\mathrm{e}_{\mathrm{ilk}} \sim \mathrm{N}\left(0, \sigma^{2}\right)$.

\section{Resultados e Discussão}

Quando o capim-coastcross foi cultivado em consórcio com Arachis pintoi, as massas de forragem foram de $2.641,2.431$ e $2.760 \mathrm{~kg} / \mathrm{ha}$, respectivamente, nas pastagens adubadas com 0, 100 e 200\% de nitrogênio, enquanto, no cultivo exclusivo, a massa de forragem foi de $2.704 \mathrm{~kg} / \mathrm{ha}$, portanto, não houve influência $(\mathrm{P}>0,05)$ da forma de cultivo (Tabela 2) sobre a massa de forragem nos períodos estudados.

A maior massa de forragem $(\mathrm{P}<0,05)$ foi observada no verão (Tabela 2 ) e os menores valores no outono e inverno, que foram superiores ao valor preconizado por Corsi \& Marta Jr. (1998), de 2.000 kg de MS/ha para o gênero Cynodon. A maior massa no verão se deve à menor proporção de matéria seca (MS) proveniente de lâminas foliares, uma vez que condições de altas temperaturas e umidade favorecem o crescimento da fração bainha + colmo verde, ocasionando maior massa residual de forragem, porém com baixa razão folha/colmo, em virtude do consumo animal.

A taxa de acúmulo total obtida no período de julho de 2003 a junho de 2004 foi de 22.604, 22.462, 27.039 e $24.440 \mathrm{~kg}$ de $\mathrm{MS} / \mathrm{ha}$, respectivamente, e não diferiu $(\mathrm{P}>0,05)$ entre as formas de cultivo (Tabela 2), provavelmente porque a pastagem era recém-implantada em área recuperada pelo sistema de integração lavoura-pecuária. No entanto, a massa de forragem na pastagem cultivada em consórcio e adubada com 200 kg de nitrogênio foi aproximadamente 4,5 toneladas superior às obtidas com $100 \mathrm{~kg}$ de nitrogênio e sem adubação, o que comprova o efeito do aumento da massa de forragem com a adubação nitrogenada. A semelhança entre as formas de cultivo também foi observada por Oliveira (2004), nesta mesma área, em seu primeiro ano de consorciação.

A maior taxa de acúmulo diário (TAD) foi observada no verão (Tabela 2), como resultado das condições favoráveis, seguido da primavera e outono. No inverno, em razão da baixa luminosidade, das temperaturas amenas e das precipitações pluviométricas reduzidas, comuns nesta época do ano, a taxa de acúmulo diário foi mais baixa (30,6 kg/ha/dia).

Os resultados comprovam diminuição da taxa de acúmulo diário de forragem e expressiva estacionalidade de produção de forragem, característica inerente às plantas $\mathrm{C}_{4}$, conforme demonstrado por Cecato (2000). A oferta de forragem na pastagem em consórcio sem adubação (Tabela 2) foi maior $(\mathrm{P}<0,05)$ que a obtida na pastagem cultivada em consórcio e adubação com 100 kg de nitrogênio, provavelmente em razão da diminuição na taxa de acúmulo da pastagem no período do outono em comparação ao verão, principalmente em virtude das variações climáticas observadas (Figura 1). Entretanto, as ofertas de forragem observadas neste trabalho foram superiores às descritas por Oliveira (2004), que estudou as mesmas formas de cultivo e observaram valores de 6,4; 5,8; 5,2 e 5,9 para CA0, CA100, CA200 e C200 respectivamente.

A elevada oferta de forragem na primavera está relacionada à retirada de animais reguladores no inverno, objetivando manter a alta disponibilidade de lâminas foliares durante o ano para mais rápida recuperação do pasto para primavera/verão. Com o início da primavera, a pastagem apresenta ótimo potencial de crescimento em relação ao inverno, comprovado pelo aumento na taxa de acúmulo diário (Tabela 2). Assim, manteve-se a carga animal baixa neste período (primavera) para que houvesse aumento na massa de forragem disponível, que estava abaixo do preconizado (2.500 kgMS/ha), caracterizando a maior oferta de forragem aos animais.

A adubação nitrogenada aumenta a produção de forragem (Tabela 2) e, conseqüentemente, permite maior taxa de lotação. A taxa de lotação na pastagem de capimcoastcross sem adubação nitrogenada foi inferior $(\mathrm{P}<0,05)$ à da pastagem em consórcio adubada com nitrogênio, $200 \mathrm{~kg} / \mathrm{ha}$ (Tabela 3). Os resultados obtidos nessas duas pastagens foram semelhantes aos encontrados no cultivo em consórcio e adubação com 100 e 200 kg de nitrogênio, o que evidencia que, além da adubação, a consorciação também pode propiciar o aumento da lotação.

Os resultados obtidos neste estudo foram inferiores aos determinados por Oliveira (2004), na mesma área, porém no ano de estabelecimento. Esse autor não observou 
Tabela 2 - Massa de forragem, taxa de acúmulo diário e oferta de forragem de Coastcross-1 consorciado com Arachis pintoi com e sem adubação nitrogenada

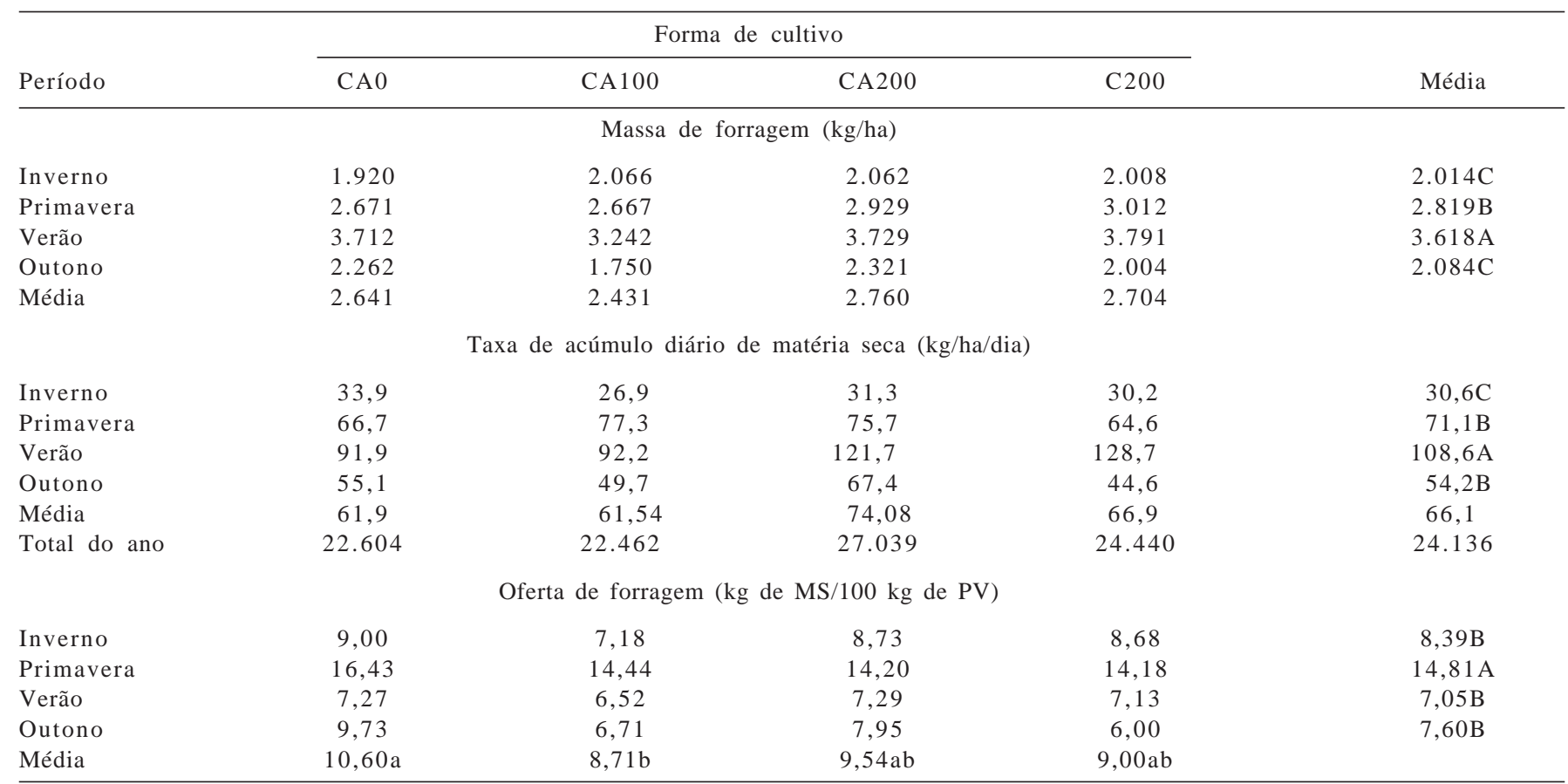

Médias seguidas de mesma letra minúscula na linha e maiúsculas na coluna não diferem a 5\% de probabilidade pelo teste Tukey.

$\mathrm{CA} 0=$ coastcross + Arachis pintoi sem nitrogênio; CA100 = coastcross + Arachis pintoi com $100 \mathrm{~kg}$ de nitrogênio; CA200 = coastcross + Arachis pintoi com 200 kg de nitrogênio e C200 = coastcross com 200 kg de nitrogênio.

diferença entre as taxas de lotação e afirmou que as lotações semelhantes são aceitáveis, uma vez que o pasto apresentou vigor de crescimento, comum em forrageiras recém-implantadas em áreas recuperadas com integração lavoura e pecuária. Esses dados comprovam a possibilidade de quadruplicar a lotação animal em áreas e pastagens do noroeste do Paraná, conforme índices regionais citados por Sá \& Caviglione (1999).

No verão, em razão das condições climáticas favoráveis, foram observadas as maiores taxas de lotação (Tabela 3), enquanto, na primavera e no outono, as taxas foram semelhantes. A baixa taxa de lotação nestes dois períodos foi ocasionada pelas condições climáticas desfavoráveis (Figura 1), uma vez que no inverno foi obtida a menor taxa de lotação (Tabela 3).

Como o desempenho animal (Tabela 3) é conseqüência da oferta de forragem, na pastagem sem adubação foi semelhante ao da pastagem adubada com $100 \mathrm{~kg}$ de nitrogênio, resultado que pode ter sido influenciado pela área, que foi utilizada em sistema de integração lavoura e pecuária em 2001.

O ganho médio diário obtido nas pastagens adubadas com 200 kg de nitrogênio, tanto do consórcio quanto de capim-coastcross em cultivo exclusivo, foi superior ao daquelas cultivadas em consórcio e adubação com 100 kg de nitrogênio, o que está relacionado ao aumento da produção de forragem e na massa de lâminas foliares, decorrente da adubação nitrogenada. As pastagens cultivadas em consórcio, sem adubação e adubada com $100 \mathrm{~kg}$ de nitrogênio, foram semelhantes $(\mathrm{P}<0,05)$ quanto ao ganho médio diário, provavelmente em virtude da maior oferta de forragem (Tabela 2) e da maior porcentagem de Arachis pintoi (Figura 2) na pastagem em consórcio sem adubação. Entretanto, quando aplicada adubação de 200 kg de nitrogênio com a presença do Arachis pintoi, não foi verificada diferença no ganho médio diário, fato justificado pela baixa disponibilidade desta leguminosa na pastagem com maior quantidade de nitrogênio (CA200) e pelo fato de a adubação nitrogenada reduzir a nodulação e a fixação de nitrogênio. O nitrogênio é um nutriente cuja presença ou ausência afeta a simbiose de várias formas (Pereira, 1982): em excesso, o nitrogênio mineral pode diminuir a eficiência simbiótica, porém, em pequenas quantidades, permite aumento no crescimento dos nódulos e maior fixação de nitrogênio - quantidades muito baixos de nitrato no solo podem ser limitantes à atividade simbiótica.

Ressalta-se que o Arachis pintoi foi utilizado em baixa proporção (Figura 2), principalmente quando houve diversidades climáticas e maiores níveis de nitrogênio. Essa espécie é suscetível ao ataque de ácaro (Marinich et al., 2002) e tem pouco crescimento vegetativo sob temperaturas 
Tabela 3 - Taxa de lotação, ganho médio diário e rendimento por área em pastagem de Coastcross-1 consorciada com Arachis pintoi com e sem adubação nitrogenada

\begin{tabular}{|c|c|c|c|c|c|}
\hline Período & \multicolumn{4}{|c|}{ Forma de cultivo } & Média \\
\hline \multicolumn{6}{|c|}{ Taxa de lotação (UA/ha) } \\
\hline Inverno & 2,35 & 2,75 & 2,47 & 2,57 & $2,54 \mathrm{C}$ \\
\hline Primavera & 3,43 & 3,94 & 4,32 & 4,31 & $4,00 \mathrm{~B}$ \\
\hline Verão & 6,91 & 6,96 & 7,72 & 8,18 & $7,45 \mathrm{~A}$ \\
\hline Outono & 3,46 & 3,85 & 4,28 & 4,32 & $3,98 \mathrm{~B}$ \\
\hline \multicolumn{6}{|c|}{ Ganho médio diário (kg/dia) } \\
\hline Inverno & 0,21 & 0,23 & 0,31 & 0,33 & $0,27 \mathrm{C}$ \\
\hline Primavera & 0,45 & 0,55 & 0,59 & 0,65 & $0,56 \mathrm{~B}$ \\
\hline Verão & 0,66 & 0,59 & 0,69 & 0,72 & $0,67 \mathrm{~A}$ \\
\hline Outono & 0,18 & 0,31 & 0,46 & 0,33 & $0,32 \mathrm{C}$ \\
\hline Primavera & 213 & 254 & 314 & 329 & $278 B$ \\
\hline Verão & 627 & 563 & 687 & 778 & $664 \mathrm{~A}$ \\
\hline Outono & 116 & 155 & 239 & 151 & $165 \mathrm{C}$ \\
\hline Total no ano & $1.053 \mathrm{~b}$ & $1.094 \mathrm{~b}$ & $1.390 \mathrm{a}$ & $1.422 \mathrm{a}$ & \\
\hline
\end{tabular}

Médias seguidas de mesma letra minúscula na linha e maiúsculas na coluna não diferem a 5\% de probabilidade pelo teste Tukey.

CA0 $=$ coastcross + Arachis pintoi sem nitrogênio; CA100 $=$ coastcross + Arachis pintoi com 100 kg de nitrogênio; CA200 = coastcross + Arachis pintoi com 200 kg de nitrogênio; e C200 = coastcross com 200 kg de nitrogênio.

mais amenas. O ganho de peso vivo médio diário, a taxa de lotação e o ganho de peso vivo por hectare (GPV/ha) na pastagem de coastcross em cultivo exclusivo adubada com $200 \mathrm{~kg}$ foram semelhantes aos obtidos na pastagem em consórcio adubada com $200 \mathrm{~kg}$ de nitrogênio.

As estimativas visuais e as medidas (material separado da dupla amostragem) (Figura 2) estiveram de acordo com as descritas por Oliveira (2004) de que o Arachis pintoi contribui pouco na matéria seca total da pastagem, como conseqüência de seu alto teor de umidade e da maior proporção de Arachis pintoi em todas as estimativas visuais em comparação às medidas.

O aumento na proporção de leguminosas em consórcio com gramíneas éalmejado, mas raramente tem sido verificado para a maioria das espécies. Entretanto, resultados dos primeiros trabalhos com Arachis pintoi indicam esta possibilidade. Santana et al. (1998), trabalhando com $B$. dictyoneura consorciada com Arachis pintoi, observaram aumento médio na participação da leguminosa de 8 para 13\% após período de 1.190 dias de pastejo. Na área utilizada neste estudo, no ano de 2002, os valores de Arachis pintoi na pastagem consorciada com coastcross não ultrapassaram $5 \%$, enquanto, no ano de 2003, chegaram a $10 \%$ da matéria seca total da pastagem (Oliveira, 2004), o que comprova a persistência dessa espécie na consorciação com gramíneas do gênero Cynodon.
Outra característica relevante é a intolerância do Arachis pintoi ao estresse hídrico, ao contrário de muitas leguminosas tropicais, cuja participação é maior na época seca do ano. Neste estudo, as condições climáticas foram decisivas para o decréscimo da leguminosa no outono e inverno do Arachis pintoi no sistema, pois no final do verão ocorreram poucas chuvas (Figura 1), o que compromete o bom crescimento desta leguminosa. Esse resultado está de acordo com relatos de Correia \& Nogueira (2004) de que o amendoim (Arachis hipogaea), ao ser submetido a estresse, reduziu progressivamente o acúmulo de massa de folhas e caules nas plantas quando houve suspensão total de rega.

O ganho diário foi maior no verão, seguido da primavera (Tabela 3), como conseqüência da maior qualidade da pastagem consumida pelos animais nesses períodos de condições climáticas adequadas para o desenvolvimento de espécies tropicais. Os ganhos no outono e no inverno não diferiram $(\mathrm{P}>0,05)$ entre si, mas foram inferiores aos obtidos nos demais períodos (Tabela 3). No final do verão, os índices pluviométricos foram baixos, o que comprometeu a qualidade da pastagem no outono, ocasionando baixos ganhos diários e por hectare (Tabela 3), possível causa dos menores ganhos em comparação aos valores obtidos por Oliveira (2004), que observou média anual de $0,54 \mathrm{~kg} / \mathrm{dia}$. Os resultados encontrados foram superiores aos descritos por 


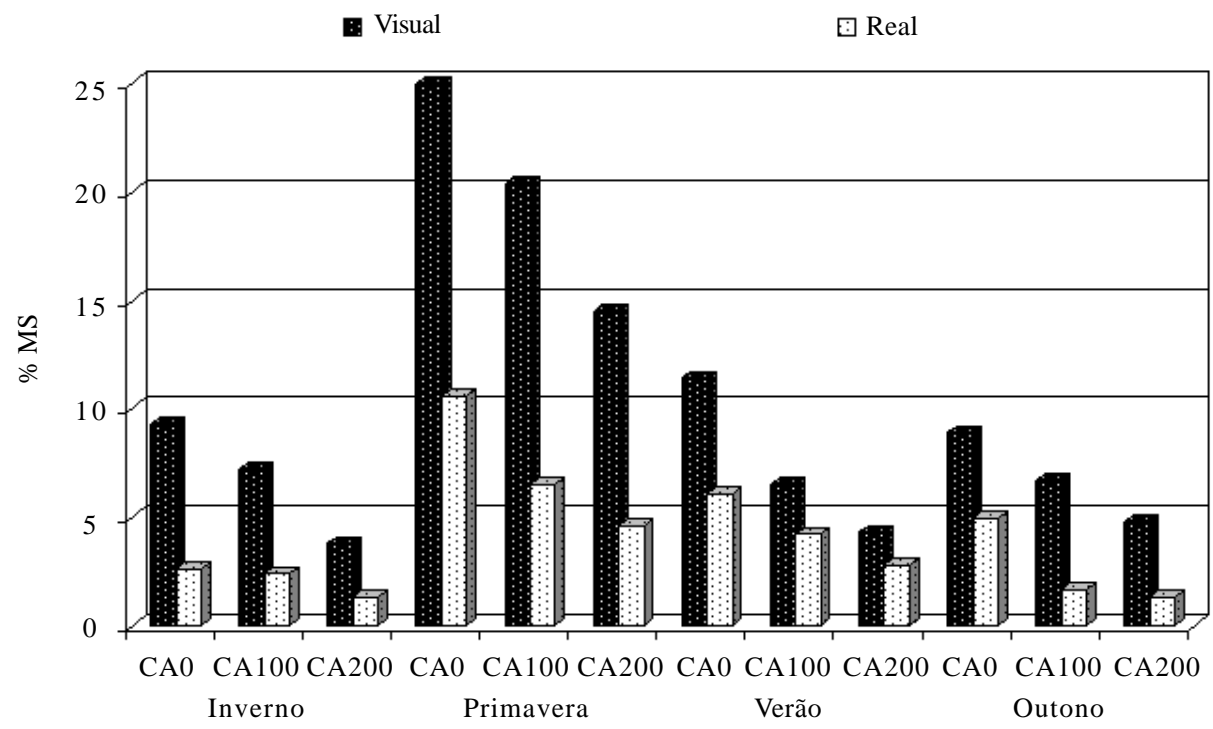

Figura 2 - Proporção de Arachis pintoi na matéria seca total e da amostra visual da pastagem consorciada com Coastcross-1 com e sem adubação nitrogenada.

Santana et al. (1998), que observaram ganhos médios de $0,55 \mathrm{~kg} /$ dia em estudo sobre consórcio de $B$. dictioneura e Arachis pintoi sob lotações de 1,6; 2,4; 3,2 e 4,0 novilhos/ha (Tabela 3).

A produtividade foi maior no verão (Tabela 3), quando correspondeu a 53\% do ganho anual, evidenciando o alto potencial de crescimento da pastagem em condições climáticas favoráveis e de manejo adequadas. A produtividade na primavera foi bem inferior à do verão, em virtude da alta oferta de forragem neste período, para melhor recuperação da pastagem após o inverno rigoroso, o que evidencia a necessidade de utilização de técnicas que permitam aumentar ou manter a produção animal, entre elas, a suplementação em pastagens.

No outono a produtividade foi semelhante à do inverno (Tabela 3), o que não era esperado, pois no outono a pastagem de capim-coastcross ainda tem bom crescimento. Entretanto, as condições climáticas desfavoráveis no final do verão (Figura 1) propiciaram esta baixa produção neste período, ocasionando menor desempenho no ano, que pode ser evitado na prática pelos produtores por meio da implantação de um planejamento forrageiro adequado.

Apesar das condições climáticas atípicas em determinadas épocas do ano, os ganhos obtidos foram muitos superiores aos encontrados em mais de 50\% dos municípios da região noroeste do Paraná, que apresentam taxas de lotação abaixo de 1,2 UA/ha e produção próxima de 120 kg/ ha/ano (Sá \& Caviglioni, 1999).

A adubação é uma ferramenta imprescindível para a boa produtividade animal, entretanto, os ganhos no segundo ano de implantação da consorciação comprovam efeito da leguminosa na fixação de nitrogênio, pois a produtividade por área e animal foi semelhante $(\mathrm{P}<0,05)$ nas pastagens em consórcio sem adubação e com 100 kg de nitrogênio. Apesar da superioridade dos ganhos nas pastagens com 200 kg de nitrogênio, este nível de fertilização pode não ser economicamente viável, em virtude dos altos custos da adubação nitrogenada.

O ganho médio diário nas pastagens, equivalente a 0,46 kg/dia durante o ano, pode ser considerado adequado, pois esse desempenho permite abate de animais com menos de 24 meses, exclusivamente em pastagens. Assim, com os dados obtidos, podem-se utilizar estratégias para antecipação da idade à cobertura e melhoria do índice de fertilidade e do maior giro de capital.

Em regiões de tradição pecuária e com potencial para produção e grãos, há constante pressão para disponibilização de áreas para a agricultura. Neste contexto, informações sobre a produção animal por unidade de área são relevantes para permitir a adoção de estratégias que tornem a atividade pecuária mais competitiva.

Ganhos por área superiores a $1.000 \mathrm{~kg}$ possibilitam que os produtores tenham melhores receitas em suas propriedades, com o uso adequado de tecnologias existentes no mercado, e dispensam a necessidade de troca de culturas.

\section{Conclusões}

A aplicação de 200 kg de nitrogênio na pastagem de capim-coastcross consorciada com Arachis pintoi 
propiciou produção de forragem e ganhos semelhantes ao obtido em cultivo exclusivo. O uso de 100 kg de nitrogênio não teve efeito positivo, em comparação ao cultivo sem adubação, o que comprova o efeito da leguminosa na fertilidade do solo. O consórcio do capim-coastcross com Arachis pintoi aumentou a proporção do capim desde o estabelecimento das culturas. Todavia, ambas as espécies apresentam semelhantes estacionalidades de produção e o Arachis pintoi tem elevada sensibilidade a déficit hídrico. A produtividade animal superior a $1.000 \mathrm{~kg} / \mathrm{ha} / \mathrm{ano}$ indica que é possível obter em regiões de arenito grandes melhoras na produção animal, por meio do manejo e de ofertas de forragem adequadas para elevar as taxas de lotação.

\section{Literatura Citada}

BARCELOS, A.O.; VILELA, L. Leguminosas forrageiras tropicais: estado da arte e perspectivas futuras. In: REUNIÃO ANUAL DA SOCIEDADE BRASILEIRA DE ZOOTECNIA, 31., 1994, Maringá. Anais... Maringá: Sociedade Brasileira de Zootecnia, 1994. p.1-56.

CAMPBELL, A.G. Grazed pastures parameters: I. Pasture drymatter production and availability in a stocking rate and grazing management experiment with dairy cows. Journal of Agriculture Science, v.67, p.211-216, 1966.

CATARUTTI, R.B.; BODDEY, R.M. Transferencia de nitrogênio das leguminosas para as gramíneas. In: SIMPÓSIO INTERNACIONAL SOBRE PRODUÇÃO ANIMAL EM PASTEJO, 1997, Viçosa, MG. Anais... Viçosa, MG: Universidade Federal de Viçosa, 1997. p.431-445.

CANTARUTTI, R.B.; NOVAIS, R.F. Quantificação da necessidade de uso de corretivos e fertilizantes em pastagens. In: SIMPÓSIO SOBRE MANEJO DA PASTAGEM, 22., 2005, Piracicaba. Anais... Piracicaba: Fundação de Estudos Agrários Luiz de Queiroz, 2005. p.181-193.

CECATO, U.; MACHADO, A.O.; MARTINS, E.N. et al. Avaliação da produção e de algumas características da rebrota de cultivares e acessos de Panicum maximum Jacq. sob duas alturas de corte. Revista Brasileira de Zootecnia, v.29, n.3, p.660-668, 2000.

CORREIA, K.G.; NOGUEIRA, R.J.M.C. Avaliação do crescimento do amendoim (Arachis hypogea L.)submetido a déficit hídrico. Revista de Biologia e Ciência da Terra, v.4, n.2, p.1-7, 2004.

CORSI, M.; MARTHA JR., G.B. Manejo de pastagens para produção de carne e leite. In: SIMPÓSIO SOBRE MANEJO DA PASTAGEM, 15., 1998, Piracicaba. Anais... Piracicaba: Fundação de Estudos Agrários Luiz de Queiroz, 1998. p.296.

COSTA, N.L. Adubação nitrogenada e consorciação de capimelefante (Pennisetum purpureum cv Cameroom) com leguminosas forrageiras tropicais. Pesquisa Agropecuaria Brasileira, v.30, n.3, p.401-408, 1995.

DA SILVA, S.C.; SBRISSIA, A.F. A planta forrageira no sistema de produção. In: SIMPÓSIO SOBRE MANEJO DE PASTAGEM A PLANTA FORRAGEIRA NO SISTEMA DE PRODUÇÃO, 17., 2000, Piracicaba. Anais... Piracicaba: Fundação de Estudos Agrários Luiz de Queiroz, 2000. p.3-21.

EMPRESA BRASILEIRA DE PESQUISA E AGROPECUÁRIA EMBRAPA. Centro Nacional de Pesquisa de Solos. Sistema brasileiro de classificação de solos. Brasília, 1999. 412p.

FOOD AND AGRICULTURE ORGANIZATION - FAO. [2002]. Datos agrícolos de Faostat. Roma: Disponível em: <http://
apps.fao.org/page/collections?subset=agriculture\&language=ES $>$ Acesso em: 30/11/2005.

FOOD AND AGRICULTURE ORGANIZATION - FAO. [2004]. Datos agrícolos de Faostat. Roma: Disponível em: <http:// apps.fao.org/page/collections?subset $=$ agriculture\&language $=\mathrm{ES}>$ Acesso em: 30/11/2005.

GARDNER, A.L. Medição dos atributos das pastagens em experimentos de pastejo. Brasília: Embrapa Sede, 1986. 197p.

HERINGER, I.; MOOJEN, E.L. Potencial produtivo, alteração da estrutura e qualidade da pastagem de Milheto submetida a diferentes níveis de nitrogênio. Revista Brasileira de Zootecnia, v.31, n.2, p.875-882, 2002.

INSTITUTO AGRONÔMICO DO PARANÁ - IAPAR. Cartas climáticas do Estado do Paraná 1994. Londrina: 1994. 49p.

JONES, R.M. Persistence of Arachis pintoi cv. Amarillo on three soil types ar Samford, south-eastern Queensland. Tropical Grasslands, v.27, p.11-15, 1993.

MARINICH, J.; AYALA, O.; GOITIA, M. et al. [2002]. Determinación de Tetranychus Urticae (Koch) en Arachis Hypogaea L. In: REUNIÓN DE COMUNICACIONES CIENTÍFICAS Y TÉCNICAS, 13., 2002, Corrientes. Anais eletrônicos... <http://agr.unne.edu.ar/Extension/Resumen/ SanidadVegetal/saveg-008.doc.> Acesso em: 20/5/2006.

MOTT, G.O.; LUCAS, H.L. The design, conduct and interpretation of grazing trials on cultivated an improved pastures. In: INTERNATIONAL GRASSLAND CONGRESS, 6., 1952, Pensylvania. Proceedings... Pensylvania: State College Press, 1952. p.1380-1385.

NASCIMENTO JR., D. Leguminosas-espécies disponíveis, fixação de nitrogênio e problemas fisiológicos para o manejo de consorciação. In: CONGRESSO BRASILEIRO DE PASTAGENS E SIMPÓSIO SOBRE MANEJO DE PASTAGEM, 8., 1986, Piracicaba. Anais... Piracicaba: Fundação de Estudos Agrários Luiz de Queiroz, 1986. p.389-411.

OliveirA, E. Desempenho animal e da pastagem de Coastcross (Cynodon dactylon [L.] Pers cv. Coastcross-1) consorciada com Arachis pintoi (Arachis pintoi Krapovickas y Gregori) em área recuperada. 2004. 126f. Tese (Doutorado em Produção Animal) - Departamento de Zootecnia Universidade Estadual de Maringá, Maringá, 2004.

PEREIRA, P.A.A. Fixação biológica de nitrogênio do feijoeiro. Informe Agropecuário, v.8, p.41-46, 1982.

PIZARRO, E.A. Novel grasses and legumes germplasm: Advances and perspectives for tropical zones. In: INTERNATIONAL GRASSLAND CONGRESS, 19., 2001, Piracicaba. Proceedings... Piracicaba, 2001. (CD-ROM).

PRIMAVESI, A.C.; PRIMAVESI, O.; CORRÊA, L.A. et al. Adubação nitrogenada em capim-coastcross: efeitos na extração de nutrientes e recuperação aparente do nitrogênio. Revista Brasileira de Zootecnia, v.33, n.1, p.68-78, 2004.

SÁ, J.P.G.; CAVIGLIONE, J.H. Arenito Caiuá: capacidade de lotação das pastagens. Londrina: IAPAR, 1999. 15p. (Informe da Pesquisa, 132).

SANTANA, J.R.; PEREIRA, J.M.; REZENDE, C.P. Avaliação de Brachiaria dictyoneura Stapf com Arachis pintoi Krapov \& Gregory sob pastejo. In: REUNIÃO ANUAL DA SOCIEDADE BRASILEIRA DE ZOOTECNIA, 35., 1998, Botucatu. Anais.. Botucatu: Sociedade Brasileira de Zootecnia, 1998. p.406-408.

UNIVERSIDADE FEDERAL DE VIÇOSA - UFV. SAEG - Sistemas de Análises Estatísticas e Genéticas (Versão 7.0). Viçosa, MG: 1997. (CD-ROM).

VALLE, C.B. Genetic resources for tropical areas: achievements and perspectives. In: INTERNATIONAL GRASSLAND CONGRESS, 19., 2001, Piracicaba. Proceedings... Piracicaba, 2001. p.477-481.

WILM, H.G.; COSTELO, O.F.; KLIPPLE, G.E. Estimating forage yield by the doublé sampling method. Journal American Society of Agronomy, n.36, v.1, p.194-203, 1944. 